\title{
O FUTEBOL EM RUY CASTRO: NOTAS SOBRE AS PRODUÇÕES BIOGRÁFICAS DE NELSON RODRIGUES E GARRINCHA
}

\section{SOCCER AND RUY CASTRO: NOTES ABOUT NELSON RODRIGUES AND GARRINCHA BIOGRAPHICAL PRODUCTIONS}

\author{
Natasha Santos-Lise ${ }^{1}$ \\ Gisele Dall'Agnol Musse ${ }^{2}$ \\ André Mendes Capraro ${ }^{3}$
}

RESUMO: O objetivo do texto é analisar a construção da narrativa biográfica de Ruy Castro, a partir das obras "O Anjo Pornográfico" e "Estrela Solitária", tomando por base as relações de texto e contexto de Antonio Candido (2000), já que se considera, aqui, a biografia enquanto gênero literário de fronteira. A partir da análise, conta-se com duas narrativas de naturezas distintas e inversas: uma voltada à construção de um ícone, a partir da superação de uma série de "ímãs demoníacos"; e outra voltada à narrativa de desconstrução de um herói, a partir da destruição de mitos e revelação da doença (alcoolismo).

Palavras-chave: Literatura. Biografia. Gênero de Fronteira. Futebol.

ABSTRACT: The aim of this paper is to analyze Ruy Castro's biographical narrative construction, regarding the literary "O Anjo Pornográfico" and "Estrela Solitária", based in the relations between the text and the context developed for Antonio Candido (2000), since the biography is considered a boundary literary genre. From the biographical constructions analysis, we have two different narratives: one focused in the construction of an icon, from "evil force" overcoming; and the second focused in a hero deconstruction narrative, from the myths destruction and the disease development (alcoholism).

Key Words: Literature. Biography. Boundary genre. Soccer.

INTRODUÇÃO

[...] a cada livro, sempre procurei ouvir mais gente e mais vezes as fontes. Por isso, cada biografia tomou mais tempo que a

\footnotetext{
${ }^{1}$ Doutora em Educação Física, pela Universidade Federal do Paraná (UFPR).

${ }^{2}$ Graduada em Educação Física, pela Universidade Federal do Paraná (UFPR).

${ }^{3}$ Doutor em História e professor do curso de Educação Física da Universidade Federal do Paraná (UFPR).
} 


\section{HISTÓRIA \\ O FUTEBOL EM RUY CASTRO: NOTAS SOBRE AS PRODUÇÕES BIOGRÁFICAS DE NELSON RODRIGUES E GARRINCHA \\ Natasha Santos-Lise \\ Gisele Dall'Agnol Musse \\ André Mendes Capraro}

anterior: dois anos para "O anjo pornográfico", três para "Estrela solitária", cinco para "Carmen - Uma biografia" (CASTRO, 11 mar. 2013). ${ }^{4}$

O objetivo do presente texto é analisar a construção da narrativa biográfica de Ruy Castro, a partir das obras "O Anjo Pornográfico" e "Estrela Solitária" - as biografias de, respectivamente, Nelson Rodrigues e Garrincha -, tomando por base as relações de texto e contexto desenroladas por Antonio Candido (2000), considerando a biografia um gênero de fronteira.

Pois bem. Jornalista e escritor, Ruy Castro já passou pelos principais veículos da imprensa brasileira e, atualmente, é colunista do jornal Folha de São Paulo. Já venceu três prêmios Jabuti e, entre seus livros de reconstituição histórica ou biográfica, podem-se mencionar: "Chega de saudade" (1990, sobre a Bossa Nova), "O anjo pornográfico" (1992, sobre Nelson Rodrigues), "Estrela solitária” (1995, sobre Garrincha), "Ela é carioca" (1999, sobre Ipanema), "Carnaval no fogo" (2003, sobre o Rio) e "Carmen - Uma biografia" (2005, sobre Carmen Miranda). (CENTRO CULTURAL BARCO, 2013) $)^{5}$ Em 1992, escreveu "O anjo pornográfico - a vida de Nelson Rodrigues", retratando as desventuras pessoais, bem como as dificuldades profissionais de um escritor considerado "pornográfico" e maldito. Três anos mais tarde, escreveria "Estrela solitária: um brasileiro chamado Garrincha", em que trouxe à tona uma série de problemas desconhecidos pelo grande público.

Essa ideia de trazer o desconhecido ao público trouxe alguns problemas a Ruy Castro, que sofreu sérias desavenças com a família Rodrigues, mas, principalmente, se indispôs com a família de Garrincha, devido a discordâncias desta com o conteúdo apresentado na biografia. Dessa forma, Castro precisou disputar judicialmente pelo

\footnotetext{
${ }^{4}$ Trecho de entrevista concedida ao Centro Cultural Barco, em 11 de março de 2013, a qual se encontra, na íntegra, disponível no site: <http://barco.art.br/ruy-castro-fala-sobre-biografia/>.

${ }^{5}$ Castro mantém, ainda, uma tênue relação com a ficção, em "Bilac vê estrelas" (2000), e com o futebol, em "O vermelho e o negro" (2001) - além de selecionar crônicas futebolísticas de Nelson Rodrigues, as quais foram publicadas nos livros "A Pátria em Chuteiras" e "À Sombra das Chuteiras Imortais". Informações disponíveis no site da Companhia das Letras. Disponível em: <http://www.companhiadasletras.com.br/autor.php?codigo=00092\#none>. Acesso em: 28 mar. 2013.
} 
O FUTEBOL EM RUY CASTRO: NOTAS SOBRE AS PRODUÇÕES BIOGRÁFICAS DE NELSON RODRIGUES E GARRINCHA

Natasha Santos-Lise

Gisele Dall'Agnol Musse

André Mendes Capraro

direito de manter a publicação circulando, pois as dez filhas do jogador alegaram não permitir a veiculação da obra e afirmaram que, tampouco, foram consultadas a respeito (SCHMIDT, 1997).

Além do vínculo com a literatura, Ruy Castro sofreu por muito tempo com o problema do alcoolismo e foi daí que surgiu a biografia de Garrincha. O intuito não era tratar de futebol, mas do alcoolismo, trazendo o jogador como fio da narração (LITERATURA NA ARQUIBANCADA, 2012).

Pensando categorias como o envolvimento e o distanciamento do escritor, quanto à sua produção, a questão que norteia o presente trabalho é a seguinte: de que recursos narrativos Ruy Castro se utiliza na escrita das biografias de Nelson Rodrigues e Garrincha? Para tal, é necessário, antes, pensar sobre o gênero biografia...

BIOGRAFIA, UM GÊNERO FRONTEIRIÇO

[...] quero ressaltar que o gênero biográfico emerge na história e no jornalismo no bojo de um processo de aproximação destas áreas com a literatura, o que implica uma incorporação do elemento ficcional e a adoção de determinados estilos e técnicas narrativas (SCHMIDT, 1997, p. 8).

Benito Schmidt (1997), ao buscar aproximações e afastamentos entre as biografias produzidas por jornalistas e historiadores, começa por apontar a proximidade à literatura enquanto o principal traço característico das produções biográficas contemporâneas. No que se refere à prática biográfica realizada por jornalistas, Schmidt destaca o diálogo com o movimento do New Journalism, que surge na década de 1960 nos Estados Unidos, enquanto o uso de técnicas ficcionais de escrita em textos de não-ficção (SCHMIDT, 1997).

Mas, tal como afirma o Schmidt, esta seria apenas uma moderna forma da comum corrente jornalística: o jornalismo literário. Ora, o jornalismo literário era já uma prática muito recorrente nos jornais brasileiros do início do século $\mathrm{XX}$, quando muitos 


\section{HISTÓRIA \\ O FUTEBOL EM RUY CASTRO: NOTAS SOBRE AS PRODUÇÕES BIOGRÁFICAS DE NELSON RODRIGUES E GARRINCHA \\ Natasha Santos-Lise \\ Gisele Dall'Agnol Musse \\ André Mendes Capraro}

literatos escreviam colunas diariamente, como fonte de renda ${ }^{6}$, acabando por imprimir tons de literatura na narrativa de determinado fato do cotidiano. O jornal Critica, da família de Nelson Rodrigues, por exemplo, já figurava de modo muito próximo a esta perspectiva, exagerando os fatos e lapidando notícias, no sentido de torná-las mais atraentes $^{7}$ (CASTRO, 1992; SANTOS, 2012). Tal modo de escrever a notícia, todavia, afastar-se-ia cada vez mais da literatura, com a especialização dos jornais, que passam a buscar maior proximidade ao tratamento neutro e objetivo do fato (LUCA, 2008).

Voltando à biografia, pode-se compreendê-la, portanto, enquanto um gênero constituído a partir do tratamento literário - ou linguagem literária - dos dados e entrevistas (as fontes, em sentido geral) acerca do biografado. Sob esta perspectiva, segundo Borges (2008) e Schmidt (1997), há biografias que tendem a ser mais literárias do que outras - aquelas seriam as escritas por jornalistas e estas, por historiadores.

Para Borges (2008, p.212),

[...] a maioria das biografias realizadas não parece satisfazer os historiadores, por oscilar entre uma idealização simplista do personagem e falsas polêmicas em torno de pessoas famosas, visando a uma grande vendagem; além disso, muitas se comprazem no anedótico, não no essencial.

\footnotetext{
${ }^{6}$ Nomes como Carlos Drummond de Andrade, Machado de Assis, José de Alencar, João do Rio, José Lins do Rego, Mário e Oswald de Andrade e, posteriormente, Nelson Rodrigues, viam no jornal um veículo de renda, que a publicação de livros não dava conta (CANDIDO, 1992; CAPRARO, 2007; SANTOS, 2012).

${ }^{7}$ No que se refere à relação entre literatura e jornalismo, esta fica evidenciada com base em dois aspectos essenciais: o primeiro deles é a necessidade de que literatos publicassem em jornais, dada a pouca vendagem de livros (SANTOS, 2012); e o segundo, como que por consequência, é o surgimento da crônica, tratada como um gênero literário de menor grandeza - tendo em vista sua posição na intersecção entre literatura e notícia -, nasceu do jornal e, portanto, uma de suas principais características é exatamente a mesma efemeridade atribuída às manchetes. Sobre a origem da crônica moderna, Antonio Candido (1992) coloca o decênio de 1930 como o momento quando esta se estabelece no Brasil. Enquanto um gênero genuinamente brasileiro, a crônica teria derivado dos folhetins, os quais foram reduzindo de tamanho e deixando de informar, ou comentar, para apenas divertir - muito embora não deixe completamente de fazê-lo.
} 


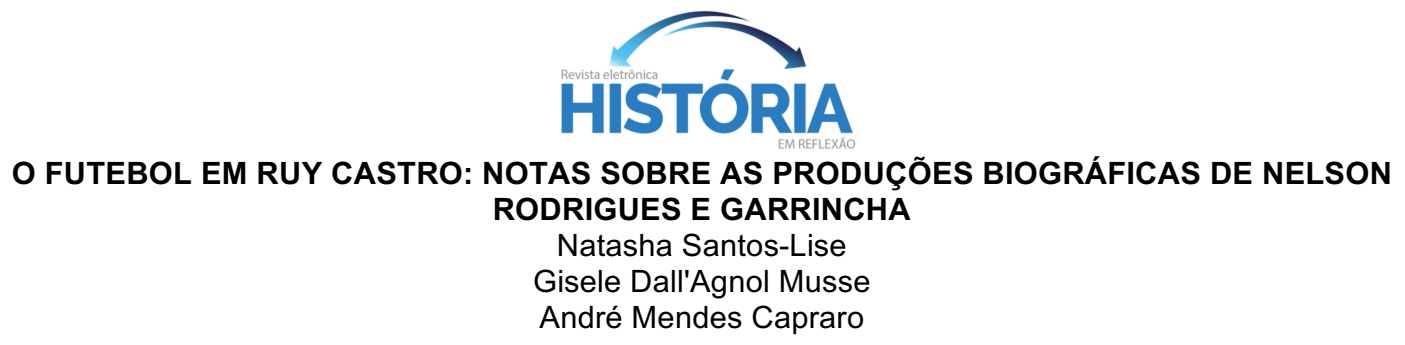

Como que complementando a concepção da autora, Schmidt (1997) aponta as minúcias que apenas o historiador vê, respaldando-se no tratamento diferenciado da fonte, com perguntas do tipo "quem produziu esta fonte?", "em que situação?”, "com que interesses?”. Assim, não haveria por parte do jornalista, "[...] uma preocupação em discutir, implícita ou explicitamente, as articulações entre vida pública e vida privada, entre cotidiano e não-cotidiano, entre atos racionais e motivações irracionais, etc." (SCHMIDT, 1997, p.17). No jornalismo, o rigor acadêmico não se coloca como primordial, como na História, e acabaria por não colocar as suas fontes sob suspeição.

Ora, ainda que coloque as fontes sob suspeição, o historiador - apesar de usuário de uma série de ferramentas metodológicas - não está isento de incrementar subjetividade a seus escritos. É o historiador que seleciona sua temática de estudo, bem como suas fontes e o período a ser analisado - o que, por si só, já aponta para a imparcialidade do estudo (LOWENTHAL, 2003). A história, tratando dos episódios significativos, não está isenta da subjetividade do pesquisador, que fala de um lugar social específico e encaminha a trajetória do texto de acordo com suas convicções. Desse modo, não é possível que se imagine a biografia produzida por um historiador como o veredito a respeito da vida de determinado personagem, pois, de maneira geral:

\begin{abstract}
A narrativa biográfica supõe uma modalidade de escrita da História profundamente imbricada nas subjetividades, nos afetos, nos modos de ver, perceber e sentir o outro. Talvez este seja o grande desafio do trabalho biográfico: ao falar do seu personagem, o biógrafo, de certa forma, fala de si mesmo, projeta algo de suas emoções, de seus próprios valores e necessidades (AVELAR, 2010, p.168).
\end{abstract}

Esse "mergulho na alma" do biografado (BORGES, 2008, p.213), torna propício o tratamento da biografia enquanto um gênero de fronteira (GINZBURG, 2004), isto é, como uma narrativa localizada na linha tênue entre ficção e contexto, já que nenhuma ilha é apenas uma ilha, mas dialogam entre si. Contemplando, portanto, aspectos textuais e contextuais. Sobre a literatura - o que se estende ao gênero de 


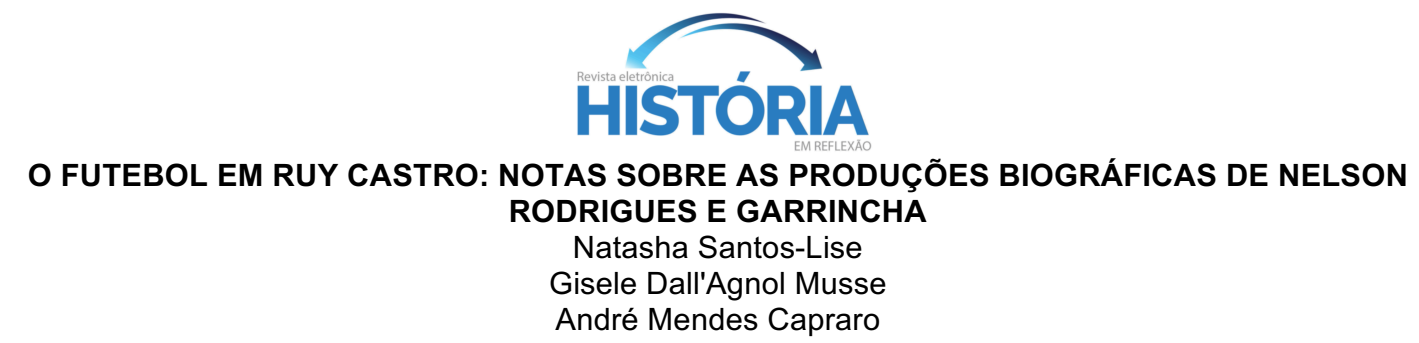

fronteira -, Candido (2000) aponta para a fusão entre texto (estética literária e a autonomia do autor) e contexto (elementos históricos e sociais) como a constituinte da obra, que deve ser considerada pelo pesquisador, o qual necessita compreender como o contexto social, junto a elementos biográficos do próprio escritor, se manifesta na produção.

Tal apontam Tavaler e Costa (2010), o questionamento sobre os biógrafos se direciona aos motivos que o levaram a tratar da vida de determinado personagem em detrimento de outro. Não se trata de negar a autonomia do autor quanto a esta escolha. Muito pelo contrário: trata-se de identificar quais as afinidades - entendidas aqui enquanto critérios pessoais - o levaram a tal.

\section{NELSON RODRIGUES, UM ANJO PORNOGRÁFICO}

Os dois anos em que trabalhei em "O anjo pornográfico" não resumem minha longa convivência com Nelson Rodrigues como seu leitor. Aprendi a ler com "A vida como ela é...", na "Ultima Hora". Desde então segui-o pelos jornais e li mais Nelson Rodrigues do que qualquer outro autor nacional ou estrangeiro (CASTRO, 1992, p.421).

Seria incorporando o próprio exagero típico da escrita rodrigueana (MARQUES 2000; ANTUNES, 2004; FACINA, 2004; SANTOS, 2012), que Ruy Castro escreveria em 1992 a biografia "O Anjo Pornográfico: a vida de Nelson Rodrigues", publicada pela Companhia das Letras. Ao que indica o próprio autor, no trecho supracitado, a iniciativa de escrever sobre a vida do dramaturgo se deu pelo contato com a obra de Rodrigues e, por isso, pode-se pensar em uma biografia escrita por um "fã".

Antonio Candido (2000, p.23), ao tratar dos conceitos de integração e diferenciação, aponta que o primeiro diz respeito a ideais que tendem a despertar em determinado público a participação nos valores comuns à sociedade de que faz parte; ao passo que o segundo tende a destacar as diferenças, as peculiaridades de determinado grupo. Tais concepções, segundo Capraro (2007), assim como as noções de envolvimento e distanciamento, definem o modo com que o autor de 


\section{HISTÓRIA \\ O FUTEBOL EM RUY CASTRO: NOTAS SOBRE AS PRODUÇÕES BIOGRÁFICAS DE NELSON RODRIGUES E GARRINCHA \\ Natasha Santos-Lise \\ Gisele Dall'Agnol Musse \\ André Mendes Capraro}

determinada obra - literária ou de fronteira - introduz o seu contexto. Não só o gênero literário, como também o perfil de escrita do autor, acaba por definir o grau de envolvimento/distanciamento com elementos contextuais.

Se a poesia tende a ser mais distante, a biografia, enquanto gênero fronteiriço, tende a ser mais envolvida e, portanto, sujeita à passionalidade do autor. No caso de Ruy Castro, o apreço pelo biografado em questão é tamanho que acaba por insinuar uma proximidade mais imaginária do que efetiva, ao afirmar sobre a "[...] longa convivência com Nelson Rodrigues - como seu leitor" (CASTRO, 1992, p.421 - grifo nosso). Ora, Castro, apesar de reconhecer que seu contato com o dramaturgo se deu, em essência, pela leitura das obras rodrigueanas - sendo Nelson o seu "amigo de bolso" -, sente-se próximo a Rodrigues, como se o conhecesse a partir de suas narrativas. Inclusive, julgando-se capaz de desvendar toda a sua vida "[...] baseado nas pistas e indicações que ele deixou em sua obra" (CASTRO, 1992, p.421), apesar de ter apenas almoçado duas vezes com biografado e o entrevistado uma vez (CASTRO, 1992, p.421).

Todavia, Castro faz também certo papel de pesquisador, ao reconhecer que, apesar de supor conhecer a vida de Nelson Rodrigues como um todo, a partir de suas leituras, foi com as fontes utilizadas que enxergou as multifaces rodrigueanas. $E$ quanto às fontes, Ruy Castro não deixou a desejar no levantamento:

Tive acesso a cartas particulares, algumas bastante íntimas, manuscritos, originais e fotos raras. (...) De janeiro de 1990 até o prelo, ouvi 125 pessoas, a grande maioria em entrevistas ao vivo, outras por telefone ou carta, quase todas mais de três vezes. O total de entrevistas chegou perto de setecentos. (...) Tudo que me disseram foi checado e rechecado entre elas (CASTRO, 1992, p.421).

Tudo isso além da leitura de matérias e produções literárias de Nelson.

Apesar de todo o material fartamente elencado, Ruy Castro demonstra, tal como mencionado ao início deste item, seu envolvimento desmedido, em especial, ao adotar uma escrita repleta de exageros e dramaticidade, aproximando-se das próprias 


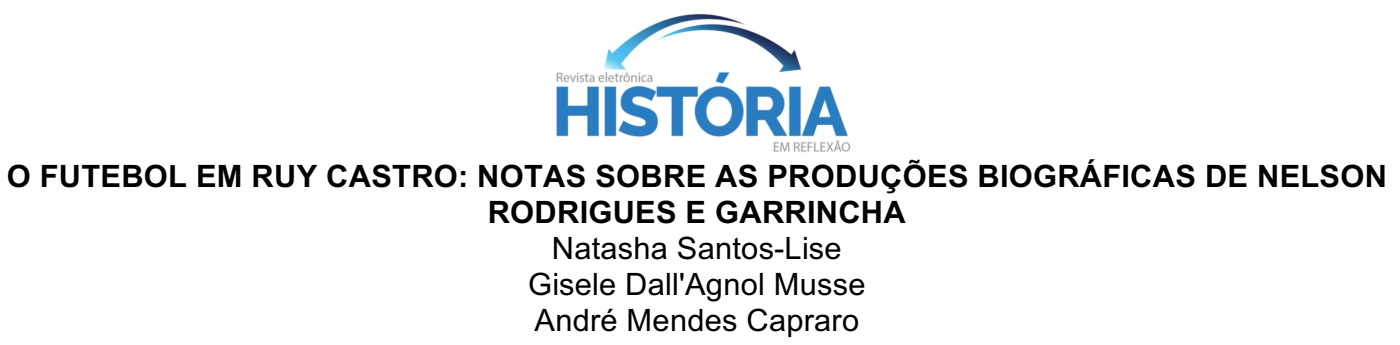

características estilísticas de Nelson Rodrigues. A começar pelo exagero, já na introdução da biografia, Castro alerta que o livro não se refere a um estudo crítico das produções dramatúrgicas do teatrólogo, relatando o que os leitores poderão encontrar em "O anjo pornográfico":

Aqui se encontrará onde, quando, como e por que Nelson escreveu todas as suas peças, romances, contos e crônicas, mas não espere "análises" ou "interpretações". O que se conta em "O anjo pornográfico" é a espantosa vida de um homem um escritor a quem uma espécie de ímã demoníaco (o acaso, o destino, o que for) estava sempre arrastando para uma realidade ainda mais dramática do que a que ele punha sobre o papel (CASTRO, 1992, p.7 - grifo nosso).

Pois bem. Ruy Castro narra a vida de Nelson Rodrigues, apontando suas produções em paralelo a determinados eventos. Todavia, o autor sequer se aproxima de relatar "[...] onde, quando, como e por que Nelson escreveu todas as suas peças, romances, contos e crônicas" (CASTRO, 1992, p.421). Destaca, sim, o possível motivo pelo qual Rodrigues acabou por se aproximar dos gêneros romance, conto e crônica, publicados em jornais - a falta de dinheiro, que o teatro não solucionava ${ }^{8}$.

Outro elemento que denota exagero é o termo "ímã demoníaco", usado para se referir a "destino". O que o leitor desatento pode não perceber é que Castro elabora uma narrativa dramática, a qual se desencadeia a partir de tal expressão, ou por outras palavras: a sucessão de tragédias por que é acometido o teatrólogo. E aí surge a justificativa para a literariedade (isto é, como uma qualidade daquilo que é literário) da biografia em questão: "Se a narrativa de 'O anjo pornográfico' lembra às vezes um romance é porque não há outra maneira de contar a história de Nelson Rodrigues e de sua família. Ela é mais trágica e rocambolesca do que qualquer uma de suas histórias, e tão fascinante quanto" (CASTRO, 1992, p.7). Se, por um lado, há as

\footnotetext{
${ }^{8}$ Esta relação entre lucro e teatro não é tão simples assim. Muito pelo contrário, trata-se de uma relação tensa, carregada por uma série de imbricações ideológicas. Para mais detalhes: SANTOS, N. Freud explicaria isso? Os sentimentos e ressentimentos do futebol em Nelson Rodrigues (1951- 70). 2012.
} 


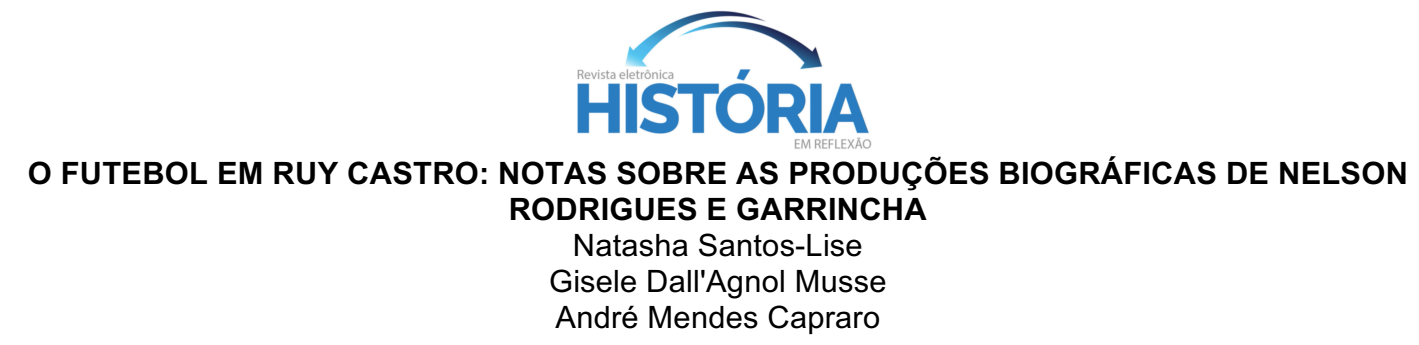

tragédias, elencadas pelo próprio Rodrigues enquanto tal, por outro, há o estilo de escrita do biógrafo. Tendo em vista que biografia se estabelece como um gênero fronteiriço, pode-se pensar que a escrita mais solta - isto é, sem citações referentes ao método ou à tese acadêmica sobre algo - aproxima o texto biográfico de uma estética mais literária.

O biógrafo constrói uma narrativa de tragédia e ascensão. Primeiramente, Ruy Castro (1992) conta a história dos avós de Nelson Rodrigues, que falecem prematuramente, deixando órfãos seu pai (Mario Rodrigues) e outros dois irmãos ainda muito jovens. Apesar de todas as circunstâncias, Mario Rodrigues se forma advogado, mas se inclina à carreira jornalística, que contagiaria os filhos. Castro vai a fundo às descrições da família Rodrigues, dando uma série de detalhes não relacionada diretamente ao biografado - como, por exemplo, a hospedagem ao então jovem Candido Portinari, colega de Roberto (irmão de Nelson) na Escola de Belas Artes.

Após uma série de idas e vindas, Mario Rodrigues funda, em 1928, o sensacionalista jornal Critica. Tal jornal passou a receber esta alcunha, devido ao fato de exagerar as notícias publicadas, como por exemplo ao se pensar a função do jovem Nelson Rodrigues no periódico. Segundo Ruy Castro (1992) - e mesmo com base nos próprios relatos de Rodrigues em textos públicos (SANTOS, 2012) - Nelson trabalhava na página policial, colhendo depoimentos na cena do crime e os retratando na notícia com certo grau de ficção, a fim de tornar as histórias mais interessantes. Pode-se dizer que é, efetivamente, a partir daí que se inicia a sucessão de tragédias para Nelson Rodrigues e sua família.

O Critica se destacava pela audácia em publicar notícias contundentes a respeito de escândalos da época e, principalmente, por ter bem marcadas as suas posições políticas, acusando sem cerimônia seus opositores (FACINA, 2004; CASTRO, 1992). E é exatamente por uma dessas notícias polêmicas e ardilosas, que Roberto Rodrigues - o segundo filho de Mario Rodrigues e ilustrador do jornal da família - acaba assassinado por Sylvia Seraphim, que tivera sua honra atacada após 


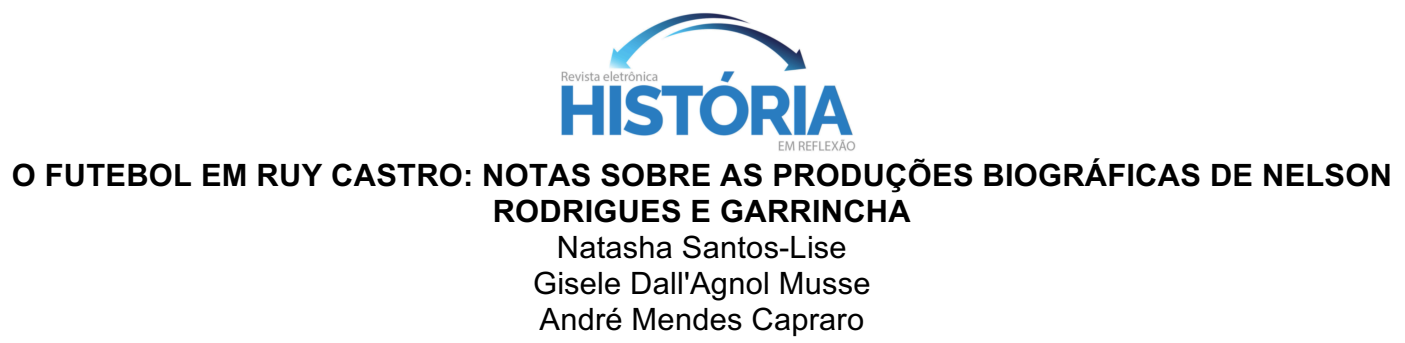

uma publicação inconveniente sobre seu divórcio ${ }^{9}$. A mulher enfurecida procurava por Mario Rodrigues e, como não o encontrou na redação de Critica, atirou em Roberto. Após a precoce morte do filho, Mario Rodrigues adoece e acaba por falecer poucos meses depois, por "[...] encefalite aguda e hemorragia" (CASTRO, 1992, p. 100). Todavia, posteriormente, Nelson Rodrigues viria a defender que a morte do pai se dera por remorso, já que Roberto morrera em seu lugar - versão também apresentada com fervor por Ruy Castro, segundo o qual, "Ninguém conseguirá penetrar no teatro de Nelson Rodrigues sem entender a tragédia provocada pela morte de Roberto" (CASTRO, 1992, p.94). Segundo a narrativa de Ruy Castro, o assassinato de Roberto desencadeou uma série de tragédias: a morte de Mario Rodrigues; o fim de Critica, com o empastelamento na Revolução de $1930^{10}$; os tempos de fome; e os problemas de saúde de Nelson Rodrigues, acarretados pelas dificuldades financeiras.

Após superar a longa crise financeira e travar uma batalha contra a tuberculose, Nelson Rodrigues passa a encarar as multidões: lança-se teatrólogo polêmico, transitando entre as alcunhas de gênio revolucionário, tarado de suspensórios e reacionário (FACINA, 2004). Junto a isso, no sentido de conseguir uma fonte de renda extra aos palcos, escreveu os contos de "A vida como ela é...", os romances sob o pseudônimo de Myrna e Suzana Flag e dedicou-se diariamente às crônicas futebolísticas (SANTOS, 2012). Casou-se, teve dois filhos, algumas amantes e mais alguns filhos. Uma delas é Daniela, "a menina sem estrela" que, por conta de uma paralisia cerebral não andava, não falava nem enxergava. Foi pela mãe de Daniela, Lúcia, que Nelson Rodrigues deixara a família - para quem, anos depois retornaria. Nelson perderia, ainda, mais dois irmãos - um para a tuberculose e outro seria vítima de uma enchente, no Rio de Janeiro. E teria um dos filhos (Nelsinho Rodrigues) preso

\footnotetext{
${ }^{9}$ A tragédia que marcou os Rodrigues foi melhor detalhada na dissertação: SANTOS, N. Freud explicaria isso? Os sentimentos e ressentimentos do futebol em Nelson Rodrigues (1951- 70). 2012.

${ }^{10}$ É-nos claro que a culpa do empastelamento incontornável não foi atribuída diretamente à morte de Roberto. Todavia, Ruy Castro, assim como Nelson Rodrigues, apontam para a muito provável possibilidade de que, se Mario Rodrigues estivesse vivo, conseguiria superar o empastelamento de maneira menos traumática.
} 
O FUTEBOL EM RUY CASTRO: NOTAS SOBRE AS PRODUÇÕES BIOGRÁFICAS DE NELSON

RODRIGUES E GARRINCHA

Natasha Santos-Lise

Gisele Dall'Agnol Musse

André Mendes Capraro

e torturado pela ditadura militar - regime pelo qual, paradoxalmente, o dramaturgo tinha simpatia (CASTRO, 1992).

Toda essa narrativa romanceada se estende por 423 páginas, divididas em 32 capítulos e muitas fontes, desde jornais a entrevistas. Todavia, elas são pouco mencionadas ou citadas - o que acentua sua semelhança a um romance. Os próprios títulos dos capítulos seguem uma lógica de roteiro romântico, iniciando pelas "Pitangas bravas"; recebendo alguns "Beijos na alma"; passando por "Sobe o pano"; "Morrer com o ser amado"; e terminando com "O anjo sobe ao céu".

Apesar de todas as polêmicas a que deu origem, bem como às tragédias vividas, Nelson Rodrigues morreu ao lado da família e acabou reconhecido enquanto um dos maiores dramaturgos do teatro moderno brasileiro. E, para Ruy Castro: "Ninguém foi mais perseguido: a direita, a esquerda, a censura, os críticos, os católicos (de quase todas as tinturas) e, muitas vezes, as plateias - todos, em alguma época, viram nele o anjo do mal, um câncer a ser extirpado da sociedade brasileira" (CASTRO, 1992, p. 8). Mais um exagero dramático, pois, apesar de ser barrado pela censura e receber diversas críticas quanto ao conteúdo de suas peças, Nelson nunca deixou de contar com a parcela que o admirava (FACINA, 2004; SANTOS, 2012).

\section{GARRINCHA, UMA ESTRELA SOLITÁRIA}

A ideia inicial era fazer um livro sobre alcoolismo, não sobre futebol. Naturalmente, não seria um ensaio, mas uma narrativa. E aí a figura do Garrincha surgiu espontaneamente como fio narrador. Era perfeito, porque eu não queria biografar um derrotado, mas um vitorioso - um homem unanimemente amado, que foi destruído pela bebida. Além disso, me daria a oportunidade de mergulhar no futebol, principalmente o de uma década que acompanhei bem: a de 50. (CASTRO, 12 jan. 2012). ${ }^{11}$

\footnotetext{
11 Trecho de entrevista concedida ao Literatura na Arquibancada, publicada em 12 de janeiro de 2013, a qual se encontra, na íntegra, disponível em <http://www.literaturanaarquibancada.com/2012/01/garrincha-estrela-solitaria.html>
} 


\section{HISTÓRIA \\ O FUTEBOL EM RUY CASTRO: NOTAS SOBRE AS PRODUÇÕES BIOGRÁFICAS DE NELSON RODRIGUES E GARRINCHA \\ Natasha Santos-Lise \\ Gisele Dall'Agnol Musse \\ André Mendes Capraro}

Logo após a publicação de "O Anjo Pornográfico", Ruy Castro começa a escrever "Estrela Solitária: um brasileiro chamado Garrincha", segunda biografia escrita pelo autor, publicada em 1995, pela Companhia das Letras. O contato com os inúmeros textos de Nelson Rodrigues sobre Garrincha e o curto período de tempo entre a construção das biografias, levam a acreditar numa certa influência rodrigueana pela escolha do jogador como próximo personagem a ser biografado.

Na obra, Castro (1995) narra a história da vida de Garrincha, um ídolo do futebol brasileiro, mas que acabou destruído pelo alcoolismo. A riqueza de detalhes, junto a uma escrita compromissada com o belo aproximam a biografia ao romance literário. O processo de produção da obra (CANDIDO, 2000) seguiu o mesmo procedimento usado anteriormente: aprender tudo o que todos sabiam sobre o jogador, e na sequência descobrir o que poucas pessoas sabem (LITERATURA NA ARQUIBANCADA, 2012). Para isso, assim como na biografia de Nelson Rodrigues, o biógrafo entrevistou várias pessoas que conviveram diretamente com Garrincha dentro e fora do meio futebolístico, e que se dispuseram a abrir seus arquivos e compartilhar memórias ${ }^{12}$. Foram 170 pessoas entrevistadas, totalizando mais de 500 entrevistas - elemento que estabelece a obra enquanto um gênero de fronteira (CAPRARO, 2007), situado no tênue limiar entre ficção e contexto ${ }^{13}$ - ao longo de 520 páginas de memória.

A biografia segue uma ordem cronológica, cujos capítulos narram a história do biografado a cada ano, ou em períodos de dois em dois, ou três em três anos, conforme os fatos mais marcantes da vida do jogador, desde seus ancestrais (índios fulniôs), passando por sua ascensão e pelo auge de sua carreira, até a sua morte

\footnotetext{
${ }^{12}$ Segundo Halbwachs (2006), a memória é uma construção ao mesmo tempo individual e social, onde o indivíduo tende a recordar aquilo que considera importante para seu grupo.

${ }^{13}$ Cabe destacar que a perspectiva de ficção, aqui elencada, está baseada na teorização de Antonio Candido (2000), tendo em vista que está relacionada à autonomia do autor, isto é, aquilo que pode estar no campo imaginativo, sabendo da impossibilidade de se ver com clareza as fronteiras entre autonomia do autor e fato histórico - daí a perspectiva de gênero fronteiriço: é possível perceber nuances de realidade histórica, mas esta é indivisível do texto como um todo.
} 


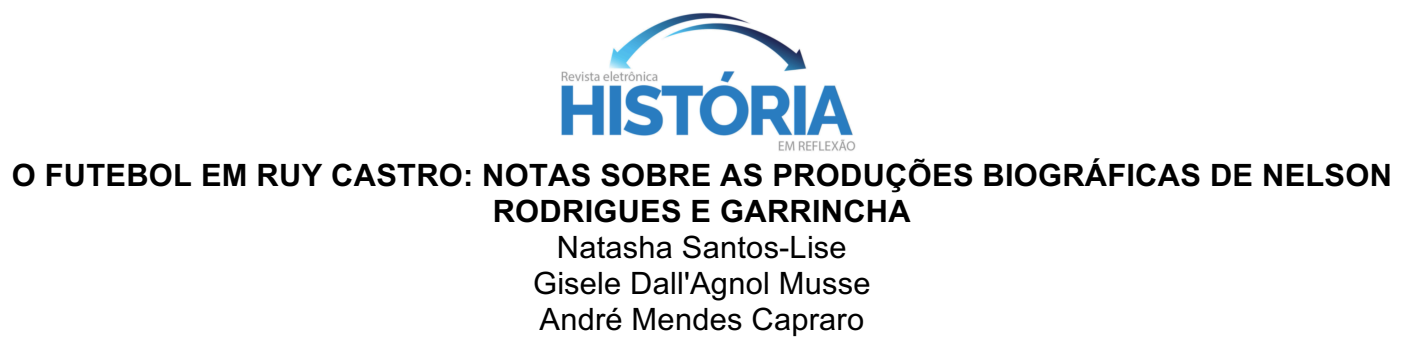

trágica. É voltando aos ancestrais de Garrincha que Ruy Castro tenta justificar o temperamento indomável do jogador, que "[...] canta bonito, mas não se adapta ao cativeiro" (CASTRO, 1995, p. 28), e o alcoolismo:

[...] Quanto a beber, os índios já produziam uma bebida espumante, de alto teor alcoólico, fermentada a partir de frutas e de raízes de aipim, com a qual os homens da tribo, incluindo o pajé e o morubixaba, embriagavam-se dias e noites nos seus feriados longos. (CASTRO, 1995, p. 7-8).

Reconstruir o personagem a partir de uma percepção cronológica desde seus ancestrais '[...] é uma 'opção' da maioria dos biógrafos, que preenchem páginas e páginas à procura dos ancestrais de seus biografados talvez por acreditarem que os ancestrais consanguíneos necessariamente moldam as gerações seguintes" (VILAS BOAS, 2006, p. 40). Segundo Lowenthal (1961, p. 119),

[...] É como se o autor quisesse impor ao leitor que seu herói, em considerável medida, fosse entendido em termos de herança biológica e regional. É uma espécie de conceito darwiniano primitivo dos fatos sociais: a tendência de colocar o peso da explicação e da responsabilidade sobre os ombros da geração anterior. $\mathrm{O}$ indivíduo em si surge como mero produto do seu passado.

Em "Estrela Solitária", Castro (1995) constrói uma narrativa de ascensão e tragédia. Como supracitado, o autor inicia a biografia contando sobre os bisavós de Garrincha, índios fulniôs apanhados pelos brancos. Na sequência, relata a infância humilde do biografado na pequena cidade de Pau Grande, no Rio de Janeiro. Os primeiros anos de Garrincha foram vivenciados de forma livre e quase que selvagem: vivia descalço e no meio do mato, nadava no rio Inhomirim, caçava passarinhos, pescava e jogava futebol de pelada. Castro (1995) demonstra que o senso de responsabilidade e a submissão às regras não era o ponto forte de Garrincha: largou a escola no segundo ano, deixava de cumprir as tarefas que seu pai delegava para 


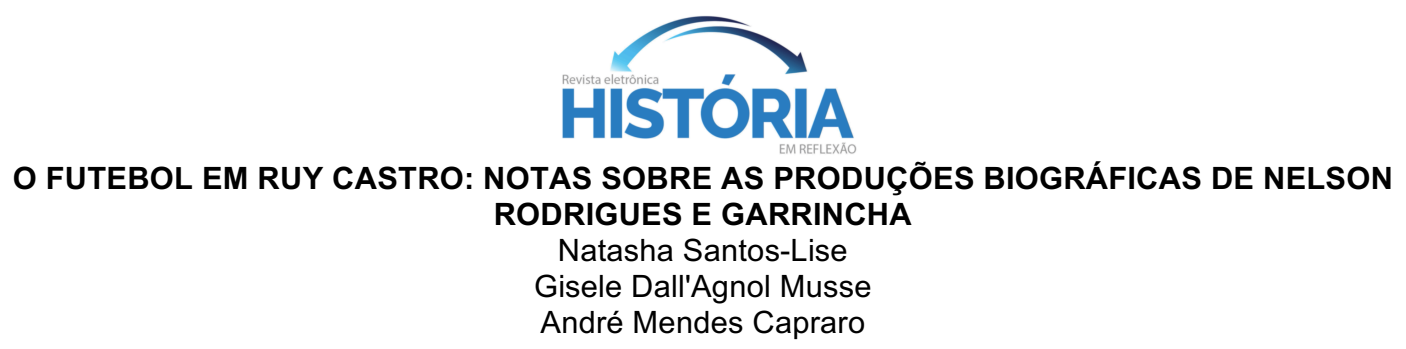

juntar-se aos outros meninos jogando futebol de pelada, e, na América Fabril ${ }^{14}$, vivia faltando, chegando atrasado ou escondendo-se para dormir em pleno horário de trabalho. Após ser rejeitado por três clubes de futebol, Garrincha conseguiu uma oportunidade para fazer um teste no Botafogo, clube em que jogou boa parte da sua carreira profissional e que the abriu as portas da seleção brasileira (CASTRO, 1995). A figura do craque e do mito é enaltecida entre as Copas do Mundo de 1958 e 1962, anos em que o Brasil conquistou o campeonato e o bicampeonato mundial, respectivamente. Ao descrever Garrincha após a Copa de 1958, o exagero tipicamente rodrigueano está presente no texto de Ruy Castro:

Garrincha nascia ali, não apenas para o mundo, mas para o próprio Brasil. A partir daquele dia, deixaram de existir botafoguenses, tricolores, rubro-negros, gremistas ou corintianos puros. Todos passariam a ser Garrincha, mesmo quando ele jogasse contra seus clubes (CASTRO, 1995, p.165).

Mas se por um lado a narrativa enfatiza a desenvoltura do herói dos gramados, por outro lado Castro (1995) descreve Garrincha como um herói tragicamente humano, que apesar de ser um "gênio intuitivo" (CASTRO, 1995, p.40) quanto ao seu jeito de driblar, arrancar e chutar, e de suas jogadas improváveis que derrubavam todos os "Joãos" a sua frente, era dotado de fraquezas humanas, se rendeu ao alcoolismo e faleceu precocemente, na pobreza. Para Kothe (1985, p.15), "O herói trágico é a verdade do destino humano, [...] o pícaro é a filosofia da sobrevivência feita gente".

É ressaltando as fraquezas humanas, como a preguiça e a indisciplina, que teimavam imperar na vida do jogador remetendo sua história à figura macunaímica, que Castro (1995) quebra a visão romântica e idealizada do mito, desconstrói a imagem de herói e transforma o jogador em um anti-herói tipicamente brasileiro. Por diversas vezes o biógrafo (1995) relata episódios em que Garrincha faltava os treinos

\footnotetext{
${ }^{14}$ Fábrica de tecidos instalada em Pau Grande e dirigida por ingleses.
} 


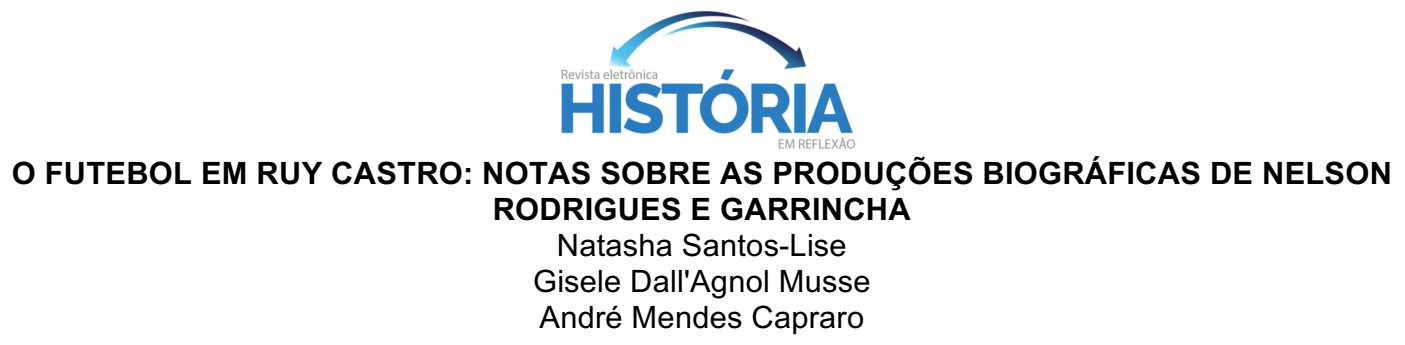

para ficar bebendo em Pau Grande com seus amigos. Episódios como este foram recorrentes ao longo da carreira de Garrincha: "[...] e, no dia seguinte, quando deveria apresentar-se à seleção até às 10 horas da noite no hotel Paysandú, foi o único a não aparecer" (CASTRO, 1995, p.243).

Porém, ao mesmo tempo em que está em ascensão e é visto como um herói (ou um anti-herói), Garrincha é retratado pelos olhos complacentes do seu biógrafo como uma pessoa simples, que mesmo no auge de sua carreira não perdeu a humildade: "[...] Podendo ter todos os luxos e confortos de um campeão do mundo, preferia viver como um operário. Ou como um camponês” (CASTRO, 1995, p.132). Dessa forma, Castro (1995) leva a acreditar que Garrincha era movido pela emoção ao invés da razão, algo semelhante à ideia do "homem cordial", de Sergio Buarque de Holanda (2008).

O biógrafo também leva o leitor a manifestar certa sensação de compaixão em relação à Garrincha devido à maneira de narrar alguns episódios situando o jogador na posição de humilhado. Castro (1995) relata uma possível aceitação de Garrincha diante um constrangimento sofrido em uma das vezes em que acompanhou Elza Soares ao estúdio para a gravação de um programa de televisão:

Garrincha acompanhava Elza e ficava sentado num banquinho atrás do palco, discreto, cabeça baixa, quase mudo, enquanto ela ensaiava. Sua presença nem sempre era bem recebida. Certa tarde foi enxotado do banquinho por um rapaz da produção: 'Não pode ficar aqui! Cai fora!' Garrincha não disse nada. Apenas levantou-se e saiu. (CASTRO, 1995, p.368).

Essa forma de narrar o sofrimento calado do jogador - "cabeça baixa, quase mudo" - reforçando a ideia de humilhado, conduzem o leitor à comoção diante do episódio narrado, situação provocada com frequência ao longo do texto. 
O FUTEBOL EM RUY CASTRO: NOTAS SOBRE AS PRODUÇÕES BIOGRÁFICAS DE NELSON RODRIGUES E GARRINCHA

Natasha Santos-Lise

Gisele Dall'Agnol Musse

André Mendes Capraro

Tentando reforçar a ideia de uma biografia fidedigna ${ }^{15}$ - do ponto de vista do autor -, a narrativa dialoga com os imaginários e representações construídas ao longo do tempo a respeito do biografado. Ao longo do texto, Ruy Castro (1995) busca se posicionar no sentido de desmentir algumas lendas a respeito do jogador, que o tornavam uma pessoa ingênua e tola. Uma delas é a famosa história de um radinho de pilha que Garrincha teria comprado na Europa, porém teria vendido por não entender nada do que o locutor estaria falando. $\mathrm{O}$ autor afirma que a história realmente ocorreu, mas quem comprou o rádio foi Hélio, o ponta-esquerda reserva do Botafogo. Garrincha teria dito a Hélio que, se ao chegar ao Brasil ele não trocasse as válvulas do rádio, ninguém entenderia o que o locutor estaria falando. Inevitavelmente, Castro (1995) cria outras lendas, como por exemplo, ao apontar que muitas dessas histórias sobre Garrincha foram inventadas por Sandro Moreyra, que as testavam com João Saldanha e depois repassava a Mario Filho - lembrando que este foi, de acordo com a historiografia do futebol, um dos maiores personagens na construção do esporte como elemento nacional (SANTOS, 2012; ANTUNES, 2004; CAPRARO, 2007). Ao contrário do que muitos pensavam, Castro (1995) afirma que Garrincha era muito esperto com o que lhe interessava - principalmente quando se tratava de mulheres e bebida. E mulheres e bebida não faltaram na vida do jogador.

A questão mais polêmica do livro é o modo direto como Ruy Castro (1995) aborda o alcoolismo. Segundo o autor, a bebida acompanha Garrincha desde seus tempos de juventude, mas foi no início da década de 1962 que o alcoolismo se acentuou e ele passou a beber tanto às claras, quanto às escondidas. Garrincha escondia bebida no quarto e em vários lugares da casa, já que não conseguia passar um dia sem beber. Depois de alguns dias numa clínica, recebia alta e voltava para as ruas, para beber. A partir do início da decadência e acentuando-se com o alcoolismo, Garrincha passa a distorcer certas coisas. Segundo Castro (1995, p.434),

\footnotetext{
15 Por mais preciso que tente ser, o biógrafo ainda insere certa subjetividade - sua, ou dos seus entrevistados - no seu texto.
} 


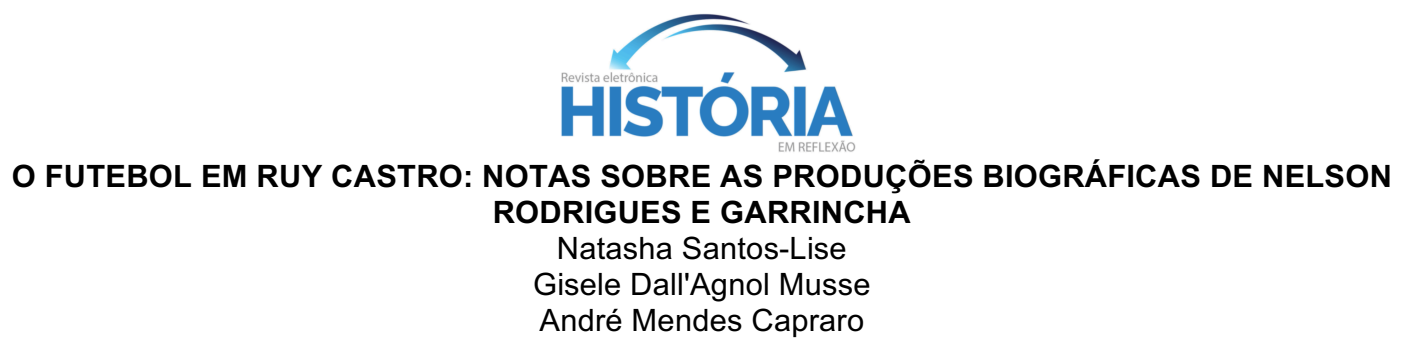

Ali começava a carreira de autocomiseração de Garrincha - uma renitente busca da piedade alheia [...] Ninguém nunca o ajudara. Todos sempre o tapearam. Fora uma vítima dos falsos amigos. Os exclusivos culpados por tudo aquilo que lhe acontecera de ruim eram os outros.

Segundo o biógrafo (2012), abordar com rigor o problema alcoolismo foi uma forma de quebrar a visão romântica e falsa pelas quais tantos se aproveitaram do jogador enquanto ele estava no auge - "Estelita começava a achar que talvez estivesse na hora de vender Garrincha. Disse isso a Palmeiro e este reagiu: 'Está louco? A torcida põe fogo na sede. Garrincha é um patrimônio do clube!'” (CASTRO, 1995, p.287) - e depois o abandonaram quando ele decaiu - "No dia de seu aniversário oficial [...] Elza deu uma festa no apartamento [...] Ninguém do Botafogo compareceu, exceto Nílton Santos e o preparador Admildo Chirol" (CASTRO, 1995, p.346).

Garrincha faleceu aos 49 anos, quase cinco anos após o primeiro surto de abstinência aguda, pobre e sem prestígio. Não podemos afirmar que o jogador foi complacente com a doença, porém o que Castro (1995) parece querer representar é a ideia de que mesmo tendo a oportunidade de largar a bebida através das várias internações, Garrincha negou o tratamento, entregando-se ao alcoolismo, ocasionando a sua morte.

Ao trazer à baila os aspectos relacionados ao alcoolismo de Garrincha - ainda que havendo certa motivação pessoal por parte de Ruy Castro, dada sua proximidade com o problema -, o biógrafo destaca aspectos que transcendem aos feitos do jogador em campo. Daí um ponto importante na desconstrução de uma figura pública e, esportivamente, aclamada, como Garrincha: destaca-se o ponto humano e problemático do jogador, que culmina com o título da própria obra. "Estrela Solitária" pode estar, de maneira mais clara, relacionada ao símbolo do Clube de Regatas Botafogo, mas também aponta para a solidão de Garrincha, ocasionada, especialmente, pelo alcoolismo. 
HISTÓRIA

O FUTEBOL EM RUY CASTRO: NOTAS SOBRE AS PRODUÇÕES BIOGRÁFICAS DE NELSON

RODRIGUES E GARRINCHA

Natasha Santos-Lise

Gisele Dall'Agnol Musse

André Mendes Capraro

\section{CONSIDERAÇÕES FINAIS}

As tragédias das vidas de Nelson Rodrigues e Garrincha, desencadeadas às margens do meio futebolístico, são submetidas por Ruy Castro a um mesmo arsenal dramático-literário, todavia com motivações distintas. Considerando-se a autonomia do autor e seu envolvimento com a obra (CANDIDO, 2000), pode-se dizer que, se a vida do dramaturgo foi envolta por uma narrativa que, embora trágica, apontava para a eminência de uma personalidade celebrada, seja no meio esportivo ou teatral; o mesmo não se pode dizer da vida do jogador, em que Castro desconstrói o ícone "Garrincha", ao relatar todas as consequências do alcoolismo.

Ora, Nelson Rodrigues foi biografado por um fã, alguém que lia suas obras e o acompanhava antes mesmo da pesquisa biográfica. Ao passo que Garrincha foi escolhido por seu problema com o alcoolismo, pelo qual também passou Ruy Castro e, após toda a dificuldade, conseguiu abandonar o vício (CASTRO, 25 jan. 2013). A ideia em "Estrela Solitária" seria tratar da doença relacionada ao alcoolismo. Para tal, Garrincha seria um fio da narração.

Desse modo, conta-se com duas narrativas de naturezas distintas e inversas: uma voltada à construção de um ícone, a partir da superação de uma série de "ímãs demoníacos"; e uma segunda voltada à narrativa de desconstrução de um herói, a partir da destruição de mitos e revelação da doença (alcoolismo).

Através da desconstrução do herói, Ruy Castro ressalta as fraquezas humanas de Garrincha mostrando o homem que existe por trás do mito, sem fazer muito romantismo para questão da bebida. É importante considerar que o biógrafo constrói a narrativa sobre o seu próprio parâmetro, ou seja, com os olhos de hoje. É um caso onde o autor começa a escrever a história conhecendo o fim do seu biografado, portanto, já sabendo que Garrincha não se daria bem no final.

Para além disso, deve-se destacar a condição de Ruy Castro, enquanto exalcoólatra, o que despertou seu interesse para tratar de personagens como Garrincha e Carmem Miranda; além de seu gosto por futebol e pela cidade do Rio de Janeiro, o que denota a empatia entre o biógrafo e seus biografados. Diferentemente da 
O FUTEBOL EM RUY CASTRO: NOTAS SOBRE AS PRODUÇÕES BIOGRÁFICAS DE NELSON RODRIGUES E GARRINCHA

Natasha Santos-Lise

Gisele Dall'Agnol Musse

André Mendes Capraro

autobiografia - em que se pode pensar em uma construção com base na memória do autobiografado -, a biografia se utiliza de outras fontes para além da entrevista. Se na autobiografia, há um pacto de leitura, em que o escritor (que é também o biografado) busca permanecer o mais próximo daquilo que considera a realidade (LEJEUNE, 2014); na biografia isso se dá por meio do uso de notícias, que auxiliam a localizar a narrativa, historicamente. Ruy Castro, por exemplo, passou mais de 20 anos visitando a Biblioteca Nacional, em busca de fontes, para as biografias de Nelson Rodrigues e Garrincha (CASTRO, 2017). Daí o sentido fronteiriço apontado previamente: conta-se com o uso de fontes, detalhadas por meio de uma narrativa solta e comprometida com a estética, em detrimento ao método histórico.

\section{REFERÊNCIAS}

ANTUNES, F. M. R. F. "Com Brasileiro Não Há Quem Possa”: futebol e identidade nacional em José Lins do rego, Mário Filho e Nelson Rodrigues. São Paulo: Unesp, 2004.

AVELAR, A. de S. A biografia como escrita da História: possibilidades, limites e tensões. Dimensões, vol. 24, 2010, p. 157-172.

BORGES, V. P. Grandezas e misérias da biografia. In: PINSKY, C (Org.). Fontes Históricas. $2^{\mathrm{a}}$ ed. São Paulo: Contexto, 2008. pp. 203 - 233.

CANDIDO, A. et. al. A Crônica. Campinas: Editora da Unicamp, 1992.

. Literatura e Sociedade. São Paulo: Queiroz, 2000.

CAPRARO, A. M. Identidades Imaginadas: Futebol e Nação na Crônica Esportiva Brasileira do Século XX. Curitiba: Departamento de História da Universidade Federal do Paraná (Tese de Doutorado), 2007.

CASTRO, Ruy. O anjo pornográfico: a vida de Nelson Rodrigues. São Paulo, Companhia das Letras, 1992.

. Estrela solitária: um brasileiro chamado Garrincha. São Paulo, Companhia das Letras, 1995. 
HISTÓRIA

O FUTEBOL EM RUY CASTRO: NOTAS SOBRE AS PRODUÇÕES BIOGRÁFICAS DE NELSON RODRIGUES E GARRINCHA

Natasha Santos-Lise

Gisele Dall'Agnol Musse

André Mendes Capraro

Há 25 anos. Folha de São Paulo, 25 jan. 2013. Disponível em: <http://www1.folha.uol.com.br/fsp/opiniao/90366-ha-25-anos.shtml>. Acesso em: 27 mar. 2013.

CASTRO, R. In CÂNDIDO. Um escritor na biblioteca - Ruy Castro. 2017. Disponível em:

<http://www.candido.bpp.pr.gov.br/modules/conteudo/conteudo.php?conteudo=1264 >. Acesso em: 15 out. 2018.

CENTRO CULTURAL BARCO. Ruy Castro fala sobre biografia. 11 mar. 2013. Disponível em: <http://barco.art.br/ruy-castro-fala-sobre-biografia/>. Acesso em: 28 mar. 2013.

FACINA, A. Santos e Canalhas: uma análise antropológica da obra de Nelson Rodrigues. Rio de Janeiro: Civilização Brasileira, 2004.

GLOBOPLAY. Ruy Castro fala sobre sua história com o álcool. 27 jun. 2017. Disponível em: <https://globoplay.globo.com/v/5969984/>. Acesso em: 15 out. 2018.

HALBWACHS, M. A Memória Coletiva. São Paulo: Centauro, 2006.

HOLANDA, S. B. de. Raízes do Brasil. São Paulo: Companhia das Letras, 2008.

LEJEUNE, Philippe. O pacto autobiográfico: de Rousseau à internet. Belo Horizonte: Editora UFMG, 2014.

LITERATURA NA AQRQUIBANCADA. Garrincha, a estrela solitária. 12 jan. 2012. Disponível em: <http://www.literaturanaarquibancada.com/2012/01/garrincha-estrelasolitaria.html>. Acesso em: 28. mar. 2013.

LOWENTHAL, D. Knowing the Past. In: The Past is a Foreign Country. 11ed. United Kingdom: Cambridge University Press, 2003.

LUCA, T. R. de. A História nos, dos e por meios dos periódicos. In: PINSKY, C (Org.). Fontes Históricas. $2^{a}$ ed. São Paulo: Contexto, 2008. pp. 203 - 233.

TAVALER, S.; COSTA, V. L. de M. Biografia em Educação Física: sua problemática e abrangência. Revista de Educação Física/UEM Maringá, v. 21, n. 1, p. 313-320, 2. trim. 2010.

SANTOS, N. Freud explicaria isso? Os sentimentos e ressentimentos do futebol em Nelson Rodrigues (1951- 70). Curitiba: Departamento de História da Universidade Federal do Paraná (Dissertação de Mestrado), 2012. 


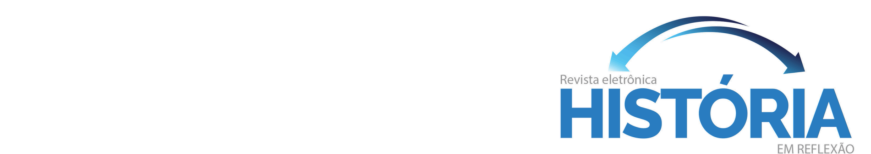

O FUTEBOL EM RUY CASTRO: NOTAS SOBRE AS PRODUÇÕES BIOGRÁFICAS DE NELSON RODRIGUES E GARRINCHA

Natasha Santos-Lise

Gisele Dall'Agnol Musse

André Mendes Capraro

SCHMIDT, B. B. Construindo Biografias... Historiadores e Jornalistas: Aproximações e Afastamentos. Revista Estudos Históricos, Rio de Janeiro, v.10, n. 19, 1997.

Artigo recebido em 15/10/2018

Artigo aceito em 16/01/2019 